\title{
A Study on Interpersonal Communication between Married Couples on Planned Parenthood
}

\author{
Sarwatay D. and Divatia A.
}

\begin{abstract}
India's population constantly exercises pressure on its limited resources making the problem of family planning and population control urgent. The government has made efforts to combat this, but the final say lies with the couple whose interpersonal communication laced with knowledge about Planned Parenthood will ultimately lead government programmes to fruition. This study investigated about the effectiveness of interpersonal communication between married couples and Planned Parenthood to establish if correlation existed and to what extent. Detailed analysis showed strong, positive correlation between levels of knowledge and effectiveness of communication. Male condoms and birth control pills were known methods of contraception among majority. The internet was the most important medium as source of information and "suitable time in life" was the most important reason for Planned Parenthood. An association between decision of parenthood adopted and effectiveness of communication existed. Doctors and family members were enablers of effective communication. This study, which has never been conducted in its current form, clearly showed how important interpersonal communication between married couples on Planned Parenthood is. Government schemes spread awareness and motivate couples for birth control and spacing. Focus on enabling couples to plan parenthood, even for their first child, should be the agenda now.
\end{abstract}

Index Terms-Interpersonal communication, planned parenthood, contraceptives, family planning.

\section{INTRODUCTION}

For a vast country like India, health and family welfare hold high priority. Pandya (2009) wrote, "At the time of Independence in 1947, health care services in India were utterly inadequate, urban-based and curative in nature. Majority of the population, especially the poor and those residing in rural areas, did not have access to modern health facilities. Consequently, the morbidity and mortality rates were quite high. Many women died while seeking abortion to get rid of unwanted pregnancy because access to contraceptives was not available. Similarly, antenatal and postnatal care and services were poor and out of reach for majority of women and their families. Improvement in the health status of the population has been one of the major thrust areas in social development programmes of India since Independence. Over the past six decades, India has built up a vast health infrastructure and manpower at primary, secondary and tertiary care levels in the government, voluntary and private sectors manned by professionals and

Manuscript received July 14, 2014; revised October 10, 2014.

The authors are with the Development Communication from Gujarat University, India (e-mail: devina.sarwatay@gmail.com, amidivatia@yahoo.co.in). para-medicals" [1].

But, these efforts never seem to be enough in the light of the country's growing population. As per Census 2011, India is a country of 1,210,193,422 persons. [2] Chandrashekhar (1953) noted, "Of the many major socio-economic issues facing present-day India, none is graver or more urgent than her population problem. Although a country's demographic situation may have many aspects, India's over-population taking the form of tremendous pressure on her limited land and other resources - is the basic issue since all programmes for improvement are either deferred or frustrated as population overstrains the capacity of education, public health, sanitation and rural recovery... The government's Planning Commission, which issued its final Report on the First Five Year Plan in 1952, went a step beyond the Ministry of Health and recommended Planned Parenthood, involving the use of scientific contraceptive methods. The Planning Commission asserted that 'a rapidly growing population is apt to become more a source of embarrassment than of help to a programme for raising standards of living. In other words, the higher the rate of increase of population, the larger are likely to be the efforts to raise per capita living standards" [3].

Pandya observed that family planning has received importance from almost every Five Year and Annual Plan starting from the First (1951-56) to the Eleventh Plan (2007-12). The government has left no stone unturned to spread the message of family planning and population control. It brought out everything from contraceptive use for males and females to the Two-Child Norm to ensure population stabilisation. This was studied by Cole (2009) who wrote, "The Two-Child Norm is used in India as a tool to stem population growth, and is found in both family planning programmes and government policy" [4].

However, detailed study of the family planning programme revealed that the concept of planned parenthood, which the government aims at by identifying women who are not old enough to have a healthy pregnancy or wish to wait before their first child is born and strategising at the policy level to advocate children by choice and not chance, did not really find execution at the service level where focus was solely aimed at spacing, quality of service and expanding contraceptive choice.

In fact, Planned Parenthood was barely mentioned and was limited to the concept of restricting unwanted pregnancies or birth spacing. Mosby's Medical Dictionary defined Planned Parenthood as, "A philosophic framework central to the development of contraceptive methods, contraceptive counselling, and family planning programs and clinics. Advocates hold that each woman has the right to decide when to conceive and bear children and that contraceptive and 
gynaecologic care and information should be available to help her become, or prevent becoming, pregnant" [5].

This rightly implies that Planned Parenthood is about the knowledge of how and exercising the choice to have a child when you are ready for it. Among several videos (part of government scheme) advocating family planning, almost all videos talked about contraceptive methods and care after the birth of at least one child. There was only one public service advertisement (PSA) that advocated the concept of Planned Parenthood as defined above. Family, elders, neighbours, friends, community, society, religion, economics, career aspirations... the list of factors affecting a couple's decision on parenthood is endless. But, despite every party's endgame to a couple's decision, the final authority lies with the couple. It is their 'interpersonal communication' which leads to the plan to have or not have a child that is important.

Orji et al. (2007) wrote, "Spousal communication in family planning is a crucial step towards increasing men's participation in safe motherhood. This is because communication between partners about childbearing and family planning is closely linked to successful contraceptive use. Interpersonal communication is a key factor in the adoption and sustained use of family planning because it allows couples to discuss and exchange information that may change strongly held beliefs and question on what may appear unclear. Communication between husband and wife enables them to know each other's attitudes toward family planning and use of contraceptives. It allows them to voice their concerns about reproductive health issues such as worries about unwanted pregnancies or sexually transmitted infections (STIs).” [6]

Does any interpersonal communication take place? Is it focussed on Planned Parenthood? What is the scenario in an urban setting? Shouldn't enablers of interpersonal communication between couples, if any, be given importance in the scheme of things?

'A Study on Interpersonal Communication between Married Couples on Planned Parenthood' will try to get answers to these questions and perhaps raise some more of them.

\section{RATIONALE}

Accurate and effective sexual and reproductive health information and its implementation among the masses is the base of any family planning programme. This depends on awareness, knowledge and access to products and services available to men and women for them to lead a healthier lifestyle. Programmes till now have largely focussed on avoiding unwanted pregnancies, birth spacing and various methods of achieving the two. There is some effort towards the true concept of Planned Parenthood.

By true concept, it is meant that a woman should have access to necessary knowledge, services and environment to decide exactly when she would like to be a mother. Enough stress cannot be laid on the pivotal role of men in decisions towards Planned Parenthood. And, in a country like India, family and community might play some role too. Nonetheless, it is believed that the final decision lies with the couple.

It is the couple whose interpersonal communication or lack of it plays some role in them having planned or unplanned children. However, what are the factors that affect an urban couple? Does familial and societal pressure into producing an offspring or economic downturn and inflation play a role? Is there any interpersonal communication happening on planned parenthood? Does the type of family you come from have any bearing on your decision? How is education important?

This study aimed to find the effectiveness of interpersonal communication between married couples and their level of knowledge about Planned Parenthood. The grounds behind this were the basic human right of a woman who is empowered enough in her person and supported steadfastly by her partner, to decide when she would plan parenthood.

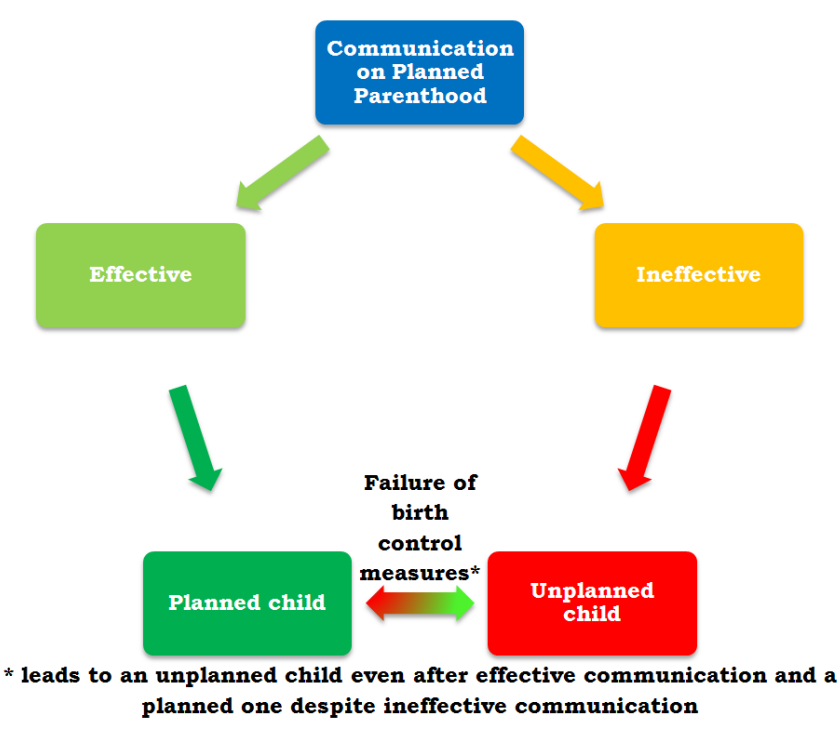

Fig. 1. Communication on planned parenthood.

\section{OBJECTIVES}

1) To find effectiveness of interpersonal communication between married couples.

2) To find level of knowledge regarding planned parenthood.

3) To find whether couples adopted Planned Parenthood and reasons behind it.

4) To study the correlation between:

- Selected personal variables and effectiveness of interpersonal communication.

- Selected personal variables and level of knowledge.

\section{HYPOTHESES}

1) There exists a relationship between selected personal variables and effectiveness of communication.

2) There exists a relationship between selected personal variables and level of knowledge.

\section{Delimitations}

1) This study is limited to urban Ahmedabad (Gujarat, India).

2) This study is limited to married and educated couples. 


\section{REVIEW OF LITERATURE}

Literature relevant to this study was reviewed under the topics of Interpersonal Communication, Communication between Couples, Communication on Parenthood and Decision-making between Couples.

Communication scholar, David Berlo (1960), talked about communication being a dynamic, ongoing, ever-changing and continuous process. [7] Psychologists Bernard and Huckins (1971) wrote, “... Things are easier to manage. Things do not ascribe meanings or accord status. Neither do they judge or evaluate. They place no pressure to impress or to convince. This happens only as a result of the interaction patterns which one has with other individuals. These patterns and interpersonal relationships are established, maintained and mediated through communication" [8].

Stewart and D'Angelo (1975) noted, "The quality of our interpersonal relationships determines who we are becoming as persons. Interpersonal communication is not just one of many dimensions of human life; it is the defining dimension, the dimension through which we become human" [9].

Barnlund (1968) noted, "Man is not a passive receptor, but an active agent in giving sense to sensation. Interpersonal communication is a complex process of creating meaning in the context of an interpersonal relationship" [10].

So, what happens when interpersonal communication takes place between opposite sexes? Tannen (1990) wrote, "Men and women use verbal messages differently" [11]. Editors Canary and Dindia (1998) elaborated, "Understanding these differences is just another way in which one can enhance interpersonal communication with others" [12], [13]. Timmerman (2002) observed, "Research does suggest that there are differences between masculine and feminine styles of communicating in that, feminine styles are more geared to establishing and maintaining relationships and masculine styles are more geared toward reaching task-related goals" [14]. Overall, interpersonal communication is a complex process that we undertake every day. It is more important when the relationship is with the spouse, or is it?

Several researchers and family therapists claimed that one of the core elements in the appreciation of the marital relationship is communication [15]. Communication is not only instrumental for marital satisfaction but even one of the most crucial factors contributing to it [16]. Esere et al (2011) seconded the above, "More than half of the failed relationships are due to the fact that there was a severe lack of communication between couples. In order to have a long and lasting relationship with someone, one must have excellent communication skills." [17] Communication is very essential in stabilising a marriage. Without it, it is nearly impossible to resolve conflicts or grow a partnership.

Through communication several problems are brought up, sorted and decisions are made. In a marriage, communication and its quality determine how well the couple is in tune with each other's needs and whether their bond has any effects on the kind of parenthood they practise. Various studies in developing nations of the world have been conducted on this subject. From Bangladesh and Pakistan in Asia, to Nigeria and Ethiopia in Africa, researchers have used various variables (demographic, socio-economic, attitudinal/ behavioural, spatial) with different tools (questionnaires, interviews and focus group discussions) to examine (using bi-variate, regression and other analyses) this topic.

Family planning communication between husbands and wives is a prerequisite for better and responsible reproductive health behaviour [18]. Couples can make better reproductive decisions if they discuss family planning matters more openly and frequently [19]. Whether to practise family planning or not, which methods to choose, when to start contraception, and the choices regarding the number and timing of children are all outcomes of inter-spousal communication [20].

The frequency of interposal communication is sometimes regarded as an indicator of safe family planning practise, where couples practise contraception appropriately and consistently without experiencing any side effects. Couples who discuss family planning matters are likely to discuss and understand the potential advantages and disadvantages of different contraceptive methods [21].

Islam, M.A. et al (2010) wrote, "Better communication between husbands and wives can also facilitate joint decision-making and balance gender roles in a family." [22] Because of the lack or absence of couple-communication about family planning, many wives believe that their husbands oppose family planning when in fact the husbands approve [23].

Studies suggested the closer a man and woman are in their levels of education, and more education they have, more likely are they to discuss and use family planning [24], [25]. A study on women in Togo, Africa showed that if a woman has some control over money then she is more likely to discuss family planning with her husband. Another study on Yoruba men (Nigeria, Africa) found that older women participate more in family planning decision-making than their younger counterparts [26].

Inter-spousal communication can be regarded as a crucial step toward increasing men's participation in family planning and reproductive health [27], [28]. Since both men and women play key roles in reproductive health, couple-communication is necessary for making responsible, healthy decisions, especially in a socio-cultural setting where informed choices are not available [29]. However, male involvement does not necessarily refer to use of male methods alone. It also includes supporting female method use which implies that husbands should communicate family planning matters with their wives. Enough stress cannot be laid on the fact that effective communication between couples leads to a better parenthood experience. Not only does the couple know exactly what and how to do, they also have the liberty to chart out the future course in their parent experience by planning a child in advance.

Waseem (2004) reported, "The review of the small-scale, interview-based studies of money in marriage highlights the ideology of privacy and of joint-ness; money is supposed to be jointly controlled by the husband and wife, with the marital unit defining its strict boundaries." [30] In couples with both partners educated and in couples in which women work for pay, both partners were significantly more likely to report that both of them participate in the final decisions than was the case in couples without education or in which the 
wife did not work for pay.

This indicated that education and women's earning status are key components of her decision- making power within the household and thus helped refine recent research on the measurement of the new constructs for women's status [31]. The influence of women's economic activity on decision-making was also shown in India in the more egalitarian setting of Tamil Nadu, but not in the gender conservative context of Uttar Pradesh [32]. Becker et al (2006) reported, "In households where the woman has no education, a larger proportion of couples agree that the husband makes the decisions than is the case when the wife is educated." [33] In a study of wives' reports on their spouses' involvement in pregnancy and birth, when the decision is being made related to an emergency situation that necessitated immediate funding for either transport orbiomedical care, it was found that wives considered their husbands to be the primary decision-makers.

Studies and articles on the subjects above gave a holistic picture on the global as well as developing countries' scenario. The review of these literature suggested that there is a dearth of studies in this area hence, an investigation was necessary.

\section{Methodology}

Research Design: This relational study was exploratory in nature to investigate possible relationships between effectiveness of interpersonal communication and Planned Parenthood to establish if correlation exists and to what extent. An analytical survey with questionnaire as a tool was used to find the phenomena mentioned above and them being affected by various independent variables in this quantitative research.

Conceptual Framework: Designed to better understand and explain different variables and their relationship with each other in the study. Both dependent and independent variables were part of this framework (Fig. 2) and it served as a roadmap to further investigation.

Independent variables: Background information of respondents including education, employment status, number of siblings and number of children of respondents and their family income.

\section{A. The Components}

Planned Parenthood: Respondent's decision or willingness to adopt Planned Parenthood

Did not plan parenthood: Respondent's decision or willingness of not adopting Planned Parenthood

Effectiveness of Communication: To find effectiveness of interpersonal communication between married couples

Level of Knowledge: To find level of knowledge regarding planned parenthood

Reasons: To find reasons for adopting and not adopting planned parenthood

It was hypothesised that selected independent variables affect level of knowledge and whether Planned Parenthood has been adopted. Effectiveness of communication was to affect and be affected by level of knowledge and had a bearing on Planned Parenthood being adopted or not. Level of knowledge was assumed to affect decisions which had their own sets of reasons. The latter influenced effectiveness of communication.

Variables: There were two types of variables in this study - independent and dependent - between which relationships were examined. Independent ones were demographic (husband's age, wife's age, number of children, years of marriage), socio-economic (husband's education, wife's education, monthly family income, employment status) and attitudinal/ behavioural (gender preference, belief in Planned Parenthood). Dependant ones were phenomena assumed to be experiencing some relationship with independent ones, like effectiveness of communication, level of knowledge and reasons for or against Planned Parenthood.

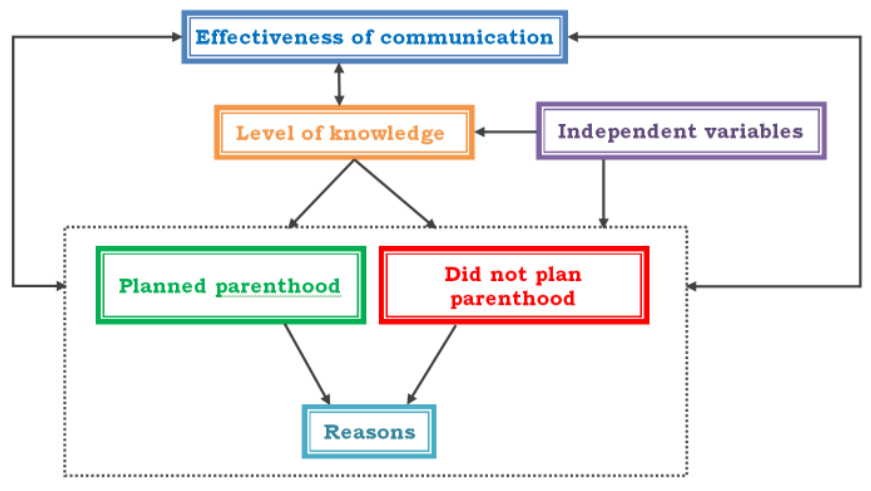

Fig. 2. Conceptual framework designed.

\section{B. Operational Definitions}

Interpersonal communication: Verbal and nonverbal interaction between individuals, typically 'one-to-one' also known as dyadic communication.

Married couples: Couples who are married and live together in urban Ahmedabad.

Planned Parenthood: A philosophic framework central to the development of contraceptive methods, contraceptive counselling, and family planning programs and clinics. Advocates hold that each woman has the right to decide when to conceive and bear children and that contraceptive and gynaecologic care and information should be available to help her become, or prevent becoming, pregnant.

Family planning: A program to regulate the number and spacing of children in a family through the practise of contraception or other methods of birth control.

Development of Tool: The study was a descriptive survey where questionnaire was used as the tool. This gave respondents a true sense of privacy and anonymity while responding questions which were considered too personal to be discussed. The questionnaire included three sections background information, methods adopted for planning parenthood and interpersonal communication. Rank analysis was used to find which were the most and least important reasons for or against Planned Parenthood. To test level of knowledge, a two-point scale having answer categories of 'Yes' and 'No' was used.

A three-point scale was made to test effectiveness of interpersonal communication. Respondents marked one of 'Always', 'Sometimes' or 'Never'. Husbands and wives were given different sets of the questionnaire to avoid 
replication of response and ensure unbiased answers.

The tool was standardised by establishing reliability and validity and pilot study was done.

Sampling Procedure: The research population was couples who were married, educated and from urban Ahmedabad. A sample of 50 couples (i.e. 50 husbands and 50 wives) was chosen. The sample was selected using simple random sampling procedure so as to avoid any bias.

Data Collection and Analysis: Of the 100 questionnaires distributed, 92 were returned which were completely filled, i.e. 46 couples. Different methods of analysis were used to study every aspect of data collected in tandem with objectives set. Frequency, percentage, means, standard deviation, correlation (continuous data) and chi-square (categorical data) analyses were used.

\section{FINDINGS}

Samples from different areas of Ahmedabad city, like Khanpur, Navrangpura, Mithakhali, Prahladnagar and Satellite were part of the study.

Detailed analysis showed that average age of the husband was 43 years, whereas that of the wife was 40 years. Majority belonged to Vaishnav caste (24\%). Next were Jains and other castes (namely Barber, Sindhis, Kshatriyas and Parsis) that came third. Brahmins, Christians and Muslims had equal shares in the pie.

Graduates made up more than half the respondent pool. More than half the husbands (63\%) were engaged in services and nearly one-fourth was businessmen. Almost half the wives $(48 \%)$ were home makers; a quarter was with services.

One-fourth belonged to families whose monthly income exceeded INR 1, 00,000 and they had the biggest share. Next place was tied by those earning between INR 30,001-50,000 (22\% each).

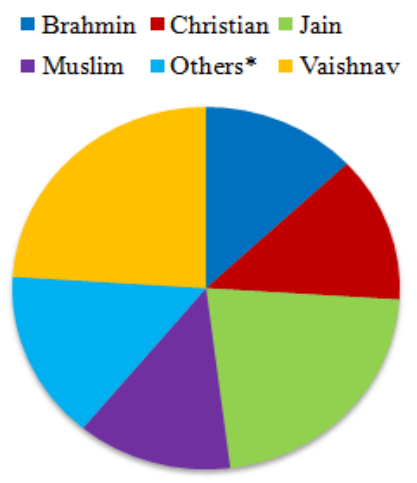

Fig. 3. Respondents' caste/religion.

\begin{tabular}{|c|c|c|c|c|c|}
\hline \multirow{2}{*}{ Employment } & \multicolumn{2}{|c|}{ Husbands } & \multirow{2}{*}{ Employment } & \multicolumn{2}{|c|}{ Wives } \\
\hline & Frequency & Percentage & & Frequency & Percentage \\
\hline Business & 12 & 26 & Business & 2 & 4 \\
\hline Retired & 1 & 2 & Home-maker & 22 & 48 \\
\hline Self-employed & 4 & 9 & Part-time & 5 & 11 \\
\hline Service & 29 & 63 & Retired & 1 & 2 \\
\hline \multirow[t]{3}{*}{ Total } & 46 & 100 & Self-employed & 3 & 7 \\
\hline & & & Service & 13 & 28 \\
\hline & & & Total & 46 & 100 \\
\hline
\end{tabular}

Two-thirds had two or less number of siblings. Nearly three-fifths of the respondents' siblings had two or less children. Most of the respondents belonged to the nuclear family type.

More than two-thirds people were unplanned births. Only one-third claimed they were the expected gender of their parents. Most (60\%) got married between 1991 and 2010.

Half the respondents had two children. Majority (72\% husbands and $70 \%$ wives) wanted two children. Most $(63 \%$ husbands and $67 \%$ wives) had no gender preference.

Doctors, family and friends proved to be very important sources of information. In fact, husbands and wives agreed on doctors (32\% each) and family (28\% each) equally. The media of internet and newspapers received the most importance as sources of information - nearly two-fifth and one-third of the respondents respectively.

"Career goals" and "right age to have children" attracted the same scores (37\% each) for husbands. The same reasons were most important for wives as well. Nearly half considered "a suitable time in life to have a child" the most important reason for Planned Parenthood. The least important reason was physical/ medical reason and managing career was the second last priority.

None of the respondents who were unaware wanted to know about Planned Parenthood. One of the reasons could be presence of awareness but lack of acceptance which leads to denial of the former. Despite knowing birth control measures do not cause infertility, respondents were wary of them.

A strong, positive correlation was found $(r=0.72)$ between levels of knowledge of husbands and wives. Nearly $40 \%$ couples had below average levels of knowledge. More women $(57 \%)$ were above average rather than being average or below average. Husbands reported awareness about male condoms the most $(96 \%)$ followed by birth control pills $(93 \%)$.

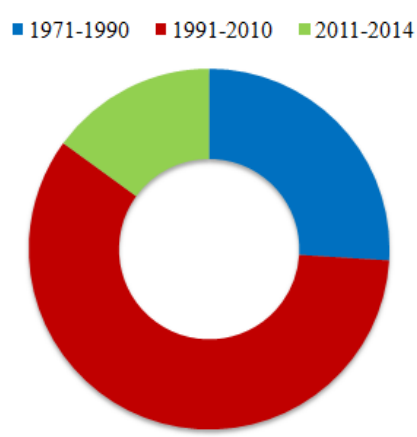

Fig. 4. Respondents' marriage year.

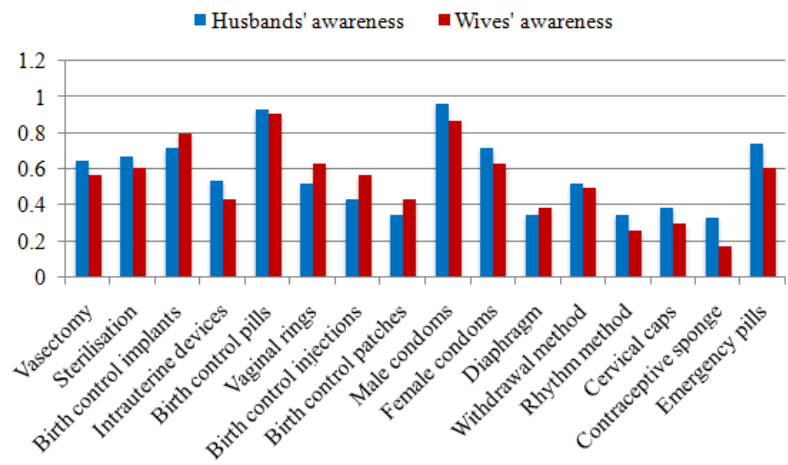

Fig. 5. Awareness about scientific methods. 
Women, in a way, followed suit by claiming awareness about birth control pills (91\%) and male condoms (87\%). More husbands than wives scored 8 or more out of 10 points and displayed a good level of awareness about scientific methods. On the other hand, there was a difference of less than $10 \%$ between the scores of wives with marginally additional of them scoring 8 or more.

Strong, positive correlation was found $(r=0.75)$ between effectiveness of communication of husbands and wives. Nearly half the husbands (48\%) had ineffective communication. Exactly half the women fell in each (effective and ineffective) category.

Respondents between 20 and 39 years thought the internet was the most important medium as source of information on Planned Parenthood. Those between 40 and 59 years of age gave almost equal importance to newspapers and television. Newspapers came second to internet once again as the most important medium. However, an equal number of graduates voted for internet and newspapers, whereas post graduates were most tech-savvy. Majority, whose monthly family income was more than INR 1, 00,000, preferred the internet.

More graduates (nearly two-thirds) were found to have effective interpersonal communication. "Suitable time in life" was the most important reason for Planned Parenthood. However, for part-timers, family's economic status was more important. The second most important reason was to get mentally prepared before having child (ren) and those employed in services felt more strongly about this than any other respondent.

Nearly $60 \%$ respondents from joint families voted for suitable time. Economic status was more important for joint families; getting mentally prepared was a priority for nuclear ones. More respondents (approximately 60\%) belonged to nuclear families. Majority had above average level of knowledge on Planned Parenthood.

TABLE II: REASONS CONSIDERED FOR PLANNED PARENTHOOD

\begin{tabular}{ccccc}
\hline Reasons considered for planned & \multicolumn{2}{c}{ Most important } & \multicolumn{2}{c}{ Least important } \\
\cline { 2 - 5 } parenthood & 13 & 22 & 10 & 17 \\
Family's economic status & 13 & 22 & 7 & 12 \\
Get mentally prepared & 4 & 6 & 6 & 10 \\
Manage career first & 1 & 2 & 32 & 53 \\
Physical/ medical reason & 29 & 48 & 5 & 8 \\
Suitable time in life & $\mathbf{6 0}$ & $\mathbf{1 0 0}$ & $\mathbf{6 0}$ & $\mathbf{1 0 0}$ \\
Total & \multicolumn{4}{c}{}
\end{tabular}

TABLE III: MONTHLY FAMILY INCOME AND MOST IMPORTANT MEDIA

\begin{tabular}{ccccccccc}
\hline \multirow{2}{*}{ Family Income } & \multicolumn{2}{c}{ Internet } & \multicolumn{2}{c}{ Newspapers } & \multicolumn{2}{c}{ Television } & \multicolumn{2}{c}{ Total } \\
\cline { 2 - 9 } & Frequency & Perrentage & Frequeny & Perentage & Frequency & Percentage & Frequency & Perentage \\
Less than 20,000 & 2 & 5.41 & 2 & 6.06 & 0 & 0 & 4 & 4.94 \\
$20,001-30,000$ & 4 & 10.81 & 6 & 18.18 & 2 & 18.18 & 12 & 14.81 \\
$30,001-40,000$ & 6 & 16.22 & 8 & 24.24 & 1 & 9.09 & 15 & 18.52 \\
$40,001-50,000$ & 9 & 24.32 & 8 & 24.24 & 3 & 27.27 & 20 & 24.69 \\
$50,001-1,00,000$ & 6 & 16.22 & 4 & 12.12 & 2 & 18.18 & 12 & 14.81 \\
More than 1,00,000 & 10 & 27.03 & 5 & 15.15 & 3 & 27.27 & 18 & 22.22 \\
Total & $\mathbf{3 7}$ & $\mathbf{1 0 0}$ & $\mathbf{3 3}$ & $\mathbf{1 0 0}$ & $\mathbf{1 1}$ & $\mathbf{1 0 0}$ & $\mathbf{8 1}$ & $\mathbf{1 0 0}$ \\
\hline
\end{tabular}

\section{Hypotheses Testing:}

$\mathbf{H}_{01}$ : There is no association between age of respondents and reasons for Planned Parenthood.
Half the respondents thought that suitable time in life was the most important reason. However, across age-groups, those between 20 and 39 years gave it more importance than those between $40-59$ years. Chi-square analysis $\left(\chi_{\text {cal }}^{2}=7.562\right.$, $\alpha=0.1, d f=2$ ) suggested the null hypotheses has been rejected and an association between age of respondents and the reasons for planned parenthood existed.

$\mathbf{H}_{02}$ : There is no association between caste and reasons for Planned Parenthood.

The most important reason, yet again, was suitable time in life across castes. Chi-square analysis $\left(\chi_{\text {cal }}^{2}=16.656 \alpha=0.1\right.$, $d f=10)$ suggested an association between caste and reasons for planned parenthood. Certain castes/ religions prohibit their followers from adopting some methods of Planned Parenthood. The above analysis was inclined to reflect the same, albeit subtly. Perhaps, other notable reasons like getting mentally prepared or family's economic status trumped the cause for prohibition. In tandem, suitable time in life remained the most important reason as this not only makes room for respondents to have child (ren) as per their goals, but also ensures a balance between other goals in general.

$\mathbf{H}_{03}$ : There is no association between education and reasons for Planned Parenthood.

For graduates, getting mentally prepared was the most important reason followed by family's economic status. But, post graduates reiterated the importance of suitable time by a large margin. Chi-square analysis $\left(\chi_{\text {cal }}^{2}=4.819, \alpha=0.1, d f=\right.$ 2 ) suggested that an association between education and reasons for planned parenthood existed.

$\mathbf{H}_{04}$ : There is no association between education and level of knowledge.

Two-thirds of the respondents were graduates and majority had below average level of knowledge on Planned Parenthood. A greater part of post graduates had above average level of knowledge. Chi-square analysis $\left(\chi^{2}\right.$ cal $=$ $5.055, \alpha=0.1, d f=2)$ suggested that an association between education and level of knowledge existed.

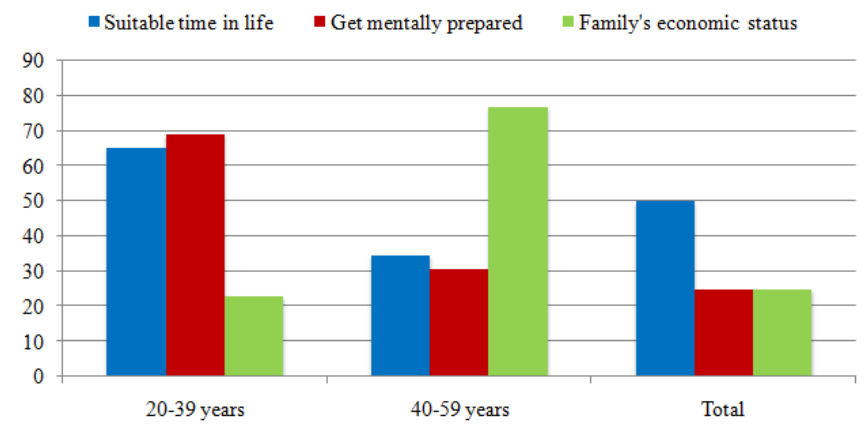

Fig. 6. Age and most important reasons.

TABLE IV: EDUCATION AND MOST IMPORTANT REASONS

\begin{tabular}{|c|c|c|c|c|c|c|c|c|}
\hline \multirow[t]{2}{*}{ Education } & \multicolumn{2}{|c|}{$\begin{array}{l}\text { Suitable time } \\
\quad \text { in life }\end{array}$} & \multicolumn{2}{|c|}{$\begin{array}{l}\text { Get mentally } \\
\text { prepared }\end{array}$} & \multicolumn{2}{|c|}{$\begin{array}{l}\text { Family's economic } \\
\text { status }\end{array}$} & \multicolumn{2}{|c|}{ Total } \\
\hline & Frequency & Percentage & Frequency & Percentage & Froqueng & Percentage & $\begin{array}{l}\text { Frequ- } \\
\text { ency }\end{array}$ & $\begin{array}{c}\text { Percen- } \\
\text { tage }\end{array}$ \\
\hline Graduate & 15 & 51.72 & 10 & 83.33 & 10 & 76.92 & 35 & 64. \\
\hline $\begin{array}{l}\text { Post } \\
\text { graduate }\end{array}$ & 14 & 48.28 & 2 & 16.67 & 3 & 23.08 & 19 & \\
\hline Total & 29 & 100 & 12 & 100 & 13 & 100 & 54 & 10 \\
\hline
\end{tabular}


$\mathbf{H}_{05}$ : There is no association between type of family and effectiveness of communication.

Majority belonged to nuclear families and more of them reported ineffective communication. Conversely, two-third joint families had effective communication. Chi-square analysis $\left(\chi_{\text {cal }}^{2}=13.229, \alpha=0.1, d f=1\right)$ suggested that an association between type of family and effectiveness of communication existed. Joint families tend to have very clear set of responsibilities for every member of the house, as encountered during data collection. It was found they get time to go out on dates and was encouraged by elders to talk about things that can cause anxiety in the relationship. This becomes a window for interpersonal communication between couples to speak about Planned Parenthood.

Nuclear families, on the other hand, were daunted by several tasks that couples had to undertake and, more often than not, they were too preoccupied with other problems to be able to find the time and/ or inclination to discuss Planned Parenthood at length or ease. These observations, to a certain extent, show why data had followed this pattern.

$\mathbf{H}_{\mathbf{0 6}}$ : There is no association between type of parenthood adopted and effectiveness of communication.

There was a marked difference between those who had ineffective communication and had adopted Planned Parenthood and their counterparts who had effective communication. Majority (90\%) in the effective category had opted for Planned Parenthood. Nearly one-third who had ineffective communication had the unplanned child (ren). Chi-square analysis $\left(\chi_{\text {cal }}^{2}=2.157, \alpha=0.1, d f=2\right)$ suggested that an association between type of parenthood adopted and effectiveness of communication exists.

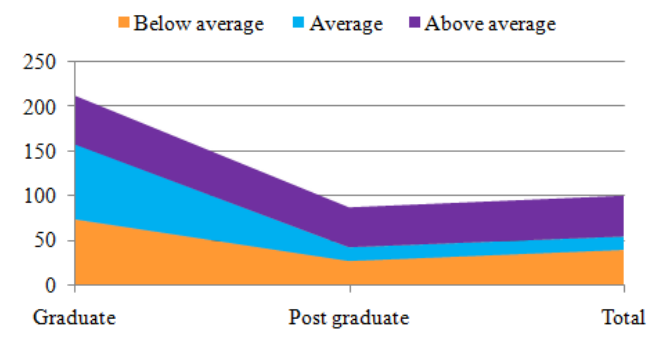

Fig. 7. Education and level of knowledge.

TABLE V: DECISION ADOPTED AND EFFECTIVENESS OF COMMUNICATION

\begin{tabular}{cccccccc}
\hline Communication & $\rightarrow$ & \multicolumn{2}{c}{ In effective } & \multicolumn{2}{c}{ Effective } & \multicolumn{2}{c}{ Total } \\
\hline Decision adopted & $\downarrow$ & Frequency & Percentage & Frequency & Percentage & Frequency & Percentage \\
\hline Planned & 22 & 62.86 & 38 & 90.48 & 60 & 77.92 \\
Unplanned & 13 & 37.14 & 4 & 9.52 & 17 & 22.08 \\
Total & $\mathbf{3 5}$ & $\mathbf{1 0 0}$ & $\mathbf{4 2}$ & $\mathbf{1 0 0}$ & $\mathbf{7 7}$ & $\mathbf{1 0 0}$ \\
\hline
\end{tabular}

$\mathbf{H}_{\mathbf{0 7}}$ : There is no association between main source of information and effectiveness of communication.

Doctors and family members proved to be enablers of effective communication. One-fourth depended on media and an almost equal share had both types of communication. Chi-square analysis $\left(\chi_{\text {cal }}^{2}=12.979, \alpha=0.1, d f=5\right)$ suggested that an association between main source of information and effectiveness of communication exists.

Conceptual Framework Redesigned: Based on findings and hypotheses testing.

Independent variables: Each dependent variable was affected by different independent ones.

Reasons: Given by respondents to plan/ not plan child (ren).

Interpersonal Communication: Effectiveness of communication engaged in by couples for decision-making.

Knowledge: On Planned Parenthood.

Decision: Either plan/ not plan parenthood.

Planned Parenthood: Respondent adopted/ will adopt.

Did not plan parenthood: Respondent did not/ will not adopt.

The study found strong evidence of various independent variables affecting effectiveness of communication and the latter, in turn, affecting decision of planning/ not planning parenthood. Independent variables were also found affecting reasons given by couples for the decision as well as level of knowledge. However, further studies will be required to investigate if and how far do reasons and knowledge affect the decision.

\section{Conclusion}

This study clearly showed how important interpersonal communication between married couples on Planned Parenthood was. Though government's family planning schemes have done plenty to spread awareness and motivate couples to practise birth control and spacing, they have yet to make leaps in enabling couples to plan parenthood, even if for their first child. It is hoped that public service announcements like 'Aisi Bhi Kya Jaldi Hai' (What is the Hurry?), 2010 [34] are refined and used more often to enable couples to make the right decisions about having or not having child (ren).

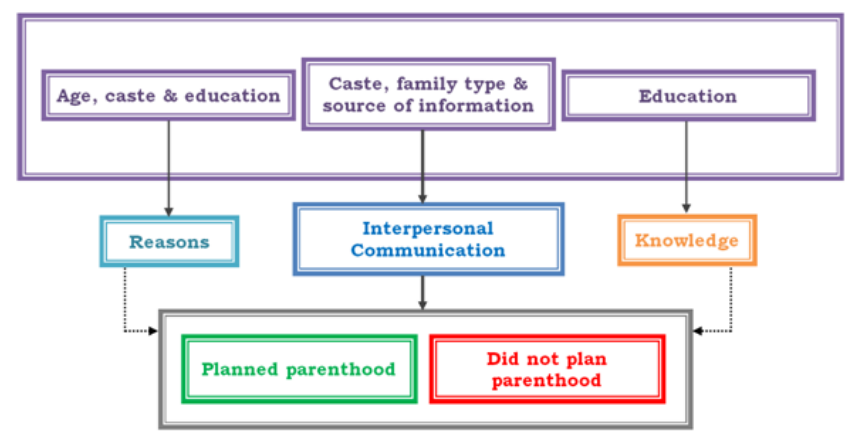

Fig. 8. Conceptual framework modified.

Another effort could be in the direction of putting up posters and handing out pamphlets on Planned Parenthood and the importance of effective interpersonal communication between couples at offices of the registrar of marriages. The role of counselling at urban health centres and government hospitals in this regard also needs to be invoked. A short credit course at under graduate colleges could be introduced.

Recommendations for further studies: This study focussed on urban Ahmedabad and married couples of all ages, castes/ religions, economic and social backgrounds. Maybe, other studies could be conducted to find out more in this and related subject areas like:

1) A comparative study between urban and rural Ahmedabad on interpersonal communication between married couples on Planned Parenthood. 
2) A study on interpersonal communication between newly married couples on Planned Parenthood.

3) Impact and implications of government family planning schemes on couples' decision-making regarding Planned Parenthood.

4) A study on reasons of married couples behind decision-making regarding planned parenthood.

5) Impact of knowledge-level on couples' decision-making on Planned Parenthood.

\section{ACKNOWLEDGEMENT}

We wish to acknowledge Dr Sonal Pandya, head of department of communication and journalism, Gujarat University. Dr Prashant Bhimani and Mr Ajay Indrekar, subject experts; administrative staff and faculty and respondents also deserve our thanks. We hope our work is found to be of as high a standard as we hold ourselves to, by the jury, our peers as well as readers. We hope this study invokes the enquirer in and inspires you.

\section{REFERENCES}

[1] R. Pandya ed., Health, Family Planning and Nutrition in India, New Delhi, India: New Century, 2009, ch. 1, p. 1.

[2] A. Bose, "Census of India 2011: some highlights," Yojana, vol. 55, pp. 6, July 2011.

[3] S. Chandrashekhar, "The prospect for planned parenthood in India," Pacific Affairs, vol. 26, no. 4, pp. 318-322, December 1953.

[4] C. Cole. (May 2009). Responding to the Two-Child Norm: Barriers and Opportunities in the Campaign to Combat Target-Oriented Population Policies in the Post-ICPD India. Centre for Health and Social Justice. [Online]. $\quad$ p. $4 . \quad$ Available: http://ww2.chsj.org/media/Intern\%20Reports/2CN_Study.pdf

[5] Mosby, Inc. Mosby's Medical Dictionary, $8^{\text {th }}$ ed., St. Louis, Mo: Mosby/ Elsevier, 2009.

[6] E. O. Orji, C. A. Adegbenro, B. I. Ogunbayo, and A. E. Oyebadejo, "Spousal communication on family planning as a safe motherhood option in sub-Saharan Africa communities," Journal of Chinese Clinical Medicine, vol. 2, pp. 328-335, June 2007.

[7] D. K. Berlo, The Process of Communication, Holt, Rinehart and Winston: New York, 1960, pp. 24.

[8] H. W. Bernard and W. C. Huckins, Dynamics of Personal Adjustment, Holbrook Press: Boston, 1971, pp. 33-42.

[9] J. Stewart and G. D'Angelo, Together: Communicating Interpersonally, Reading: Addison-Wesley, 1975, pp. 5-12.

[10] D. C. Barnlund, Perspectives on Communication, $1^{\text {st }}$ ed. Wisconsin, USA: Helix, 1968, pp. 13-39.

[11] D. Tannen, You Just Don't Understand: Women and Men in Conversation, New York: Morrow, 1990, pp. 49-64.

[12] D. J. Canary and K. Dindia, Sex Differences and Similarities in Communication: Critical Essays and Empirical Investigations of Sex and Gender in Interaction, Lawrence Erlbaum: New Jersey, 1998, pp. 427-444.

[13] L. M. Timmerman, Comparing the Production of Power in Language on the Basis of Sex, New York: Wadsworth, 2002, pp. 73-88.

[14] D. S. Becvar and R. J. Becvar, Systems Theory and Family Therapy: a Primer, University Press of America: Maryland, 1996.

[15] M. A. Fitzpatrick and D. L. Ritchie, Family Communication Patterns, Sage: California, 1994

[16] B. R. Karney and T. N. Bradbury, "The longitudinal course of marital quality and stability: a review of theory, method and research," Psychological Bulletin, vol. 118, pp. 3-34, July 1995.

[17] M. O. Esere, J. Yusuf, and J. A. Omotosho, "Influence of spousal communication on marital stability: implication for conducive home environment," Edo Journal of Counselling, vol. 4, pp. 50-61, February 2011.

[18] R. H. Chaudhury, "Female status and fertility behaviour in a metropolitan urban area of Bangladesh," Population Studies, vol. 32, pp. 261-273, 1978.

[19] W. I. DeSilva, "Husband-wife communication and contraceptive behaviour in Sri Lanka," Journal of Family Welfare, vol. 40, pp. 1-13, 1994.
[20] B. J. Feyisetan, "Spousal communication and contraceptive use among the Yoruba of Nigeria," Population Research and Policy Review, vol. 19 , pp. 29-45, 2000

[21] M. S. Islam, M. S. Alam, and M. M. Hasan, "Inter-spousal communication on family planning and its effect on contraceptive use and method choice in Bangladesh," Asian Social Science, vol. 10, pp. 189-201, January 2014.

[22] M. A. Islam, S. S. Padmadas, and P. W. F. Smith, "Understanding family planning communication between husbands and wives: a multilevel analysis of wives' responses from the Bangladesh DHS,' Genus, vol. 66, pp. 12-15, 2010.

[23] A. E. Biddlecom, J. B. Casterline, and A. E. Perez, "Spouse's view of contraception in the Philippines," International Family Planning Perspectives, vol. 32, pp. 108-115, 1997.

[24] W. I. DeSilva, "Husband-wife communication and contraceptive behaviour in Sri Lanka," Journal of Family Welfare, vol. 40, pp. 1-13, 1994.

[25] L. C. Coombs and M. C. Chang, "Do husbands and wives agree? Fertility attitudes and later behaviour," Population and Environment vol. 4, pp. 109-127, Summer 1981.

[26] A. Adewuyi and P. Ogunjuyigbe, "The role of men in family planning: An examination of men's knowledge and attitude to contraceptive use among the Yorubas," African Population Studies, vol. 18, pp. 35-49, April 2003.

[27] A. Lasee and S. Becker, "Husband-wife communication about family planning and contraceptive use in Kenya," International Family Planning Perspectives, vol. 23, pp. 15-33, March 1997.

[28] A. E. Biddlecom, J. B. Casterline, and A. E. Perez, "Spouse's view of contraception in the Philippines," International Family Planning Perspectives, vol. 32, pp. 108-115, 1997.

[29] M. Drennan, "Reproductive health: new perspectives on men's participation," Population Reports, vol. 46, pp. 3-8, 1998.

[30] S. Waseem, Household Monies and Decision-Making, Australian Government Department of Family and Community Services: Canberra, no. 23, 2004.

[31] K. O. Mason and A. M. Taj, "Women's and men's reproductive goals," Population and Development Review, vol. 26 pp. 691-723, 1987.

[32] S. J. Jejeebhoy, "Convergence and divergence in spouses' perspectives on women's autonomy in rural India," Studies in Family Planning, vol. 33, pp. 299-308, 2002.

[33] S. Becker, F. F. Becker, and C. S. Yglesias, "Husbands' and wives' reports of women's decision-making power in Western Guatemala and their effects on preventive health behaviors," John Hopkins University: Baltimore, 2006 .

[34] A. B. K. J. Hai, "What is the Hurry?" National Rural Health Mission, Public Service Advertisement, India, 2010.

Sarwatay Devina was born in Ahmedabad, India. She is a post graduate in development communication from Gujarat University, Ahmedabad (2012-14). She is continuing her studies with master of philosophy in mass communication and journalism. She was recently involved with CITE* Water Filter Evaluation, a research project on water and its treatment in households in Ahmedabad, Gujarat, India. CITE is a USAID initiative at the Massachusetts Institute of Technology focussed on evaluating technologies for the developing world. The project was undertaken in association with Indian Institute of Management, Ahmedabad and Indian Institute of Technology, Gandhinagar.

She has interned with Daily News and Analysis (newspaper), SAATH (NGO) and the moving pixels company (Audio-visual production house) apart from several research projects in the field of social science which is her area of interest. She is currently working with Amrut Mody School of Management, Ahmedabad University as a Research Associate.

Ms. Sarwatay received the Gujarat chief minister's award under the 'Kanya Kelavani Nidhi' scheme for promotion of higher education in the state of Gujarat and the $1^{\text {st }}$ rank and gold medal in her post graduate programme in Gujarat University.

Divatia Ami was born in Mumbai, India, who is a doctorate in Family Resource Management from M. S. University of Baroda in the year 2002.

She has been Faculty Associate at M.S. University, Baroda for three academic years (1995-1998). She has worked as a faculty member at ICFAI Business School for two years and H. L. Centre for professional education for two years. She is working as a member of Freelance Faculty in the field of research methodology since 2000 .

Dr. Divatia has qualified the U.G.C. test for eligibility for lectureship held on 29 June, 1997. Dr. Divatia is a member of Ethics Committee, Sterling Hospitals. 